\title{
TOWARD A PRACTICAL METHOD FOR ESTIMATING SEDIMENT-TRANSPORT RATES IN GRAVEL-BED RIVERS
}

\author{
PETER R. WILCOCK* \\ Department of Geography and Environmental Engineering, Johns Hopkins University, Baltimore, MD 21218, USA
}

Received 29 August 1999; Revised 6 December 2000; Accepted 21 September 2001

\begin{abstract}
Estimates of sediment transport rates in gravel-bed rivers are typically developed from formulae or from a sampling campaign. The former are notoriously inaccurate; the latter require a large effort and may still not achieve acceptable accuracy. A wide range of geomorphological problems, particularly those at the watershed scale, could be addressed more accurately if reliable local estimates of transport rate could be incorporated routinely into such studies. This requires a method for estimating transport rate with acceptable accuracy and a minimum of effort. A consistent approach to estimating transport is not just a matter of which formula or sampler to use; a suitable approach requires a consistent and reliable scaling of the water discharge and an integral description of the sediment that is both meaningful and practical. An approach proposed here, using a few observations of small transport rates to calibrate a transport formula, is likely to provide a superior combination of accuracy and effort and substantially reduces flow-scaling error. Small transport rates can be measured effectively using pit samplers, which allow the sampling periods needed for accurate measurements. Grain size can be represented as two fractions, sand and gravel, which capture some of the important transport dynamics and effectively represent important environmental problems within a tractable methodological approach. The approach is nearly independent of the uncertainty associated with measuring slope and bed grain-size in the field. Copyright (C) 2001 John Wiley \& Sons, Ltd.
\end{abstract}

KEY WORDS: gravel-bed rivers; sediment-transport; methods; sediment budgets; fluvial geomorphology

\section{INTRODUCTION}

A striking aspect of work on gravel-bed rivers is the wide range of methods used to estimate sediment-transport rates. These include predictions from empirical formulae, sampling using hand-held or pit traps, measuring the entire load in slot traps or settling ponds, tracking grain movement with tracer gravels and scour chains, and constructing a local sediment budget from volumetric changes in bed and bank. A considerable amount of effort typically is involved in developing transport estimates, which have remained largely in the domain of small-scale research. This is unfortunate, because many large-scale problems in fluvial geomorphology would benefit from the availability of an efficient means of estimating sediment transport rates. Topics such as watershed response to climate change, migration of sediment slugs through a channel network, or the sedimentary history of riparian ecosystems, require large-scale sediment budgets to provide historical context and to establish cause and effect. As digital technologies make it feasible to invoke sediment mass conservation throughout a watershed, the limiting factor is the resolution of the input, which depends directly on the number of locations for which reliable estimates of sediment storage and flux are developed. A method for estimating bed material flux that is both practical and accurate would allow the strong constraint of sediment mass conservation to be applied to a larger number of problems.

The need for an efficient means of estimating sediment transport extends to applied problems. It is the author's experience that the booming industry of stream restoration rarely considers the sediment a restored channel must carry. A practical method for estimating before-and-after transport rates would facilitate consideration of sediment flux in these designs. Broader questions of watershed management, such as the downstream

\footnotetext{
* Correspondence to: P. R. Wilcock, Department of Geography and Environmental Engineering, Johns Hopkins University, Baltimore, MD 21218, USA. E-mail: wilcock@jhu.edu

Contract/grant sponsor: U.S. Forest Service, Stream Systems Technology Center; Contract/grant number: 28-CCS5-019.
} 
effects of changes in land use or flow regime, also would benefit from an efficient transport methodology, which would allow tracking of sediment flux through a channel system.

A range of decisions is necessary when developing an estimate of transport rate. These extend well beyond the immediate choice between using a predictive formula or making transport measurements. The discharge can be scaled in a variety of ways in formula predictions or used directly in an empirical relationship. The range of grain sizes in transport can be represented using one, two, or many size fractions. A range of timeand space-scales can be used, depending on the level of effort possible and the purposes of the estimate. Is the total sediment load needed or the transport rate of individual size fractions? Is the annual flux through a section needed or local estimates over short time periods? Are transport rates needed only for current conditions, or is there a need to predict transport under altered conditions? The choices of formula versus sampling, flow scaling, grain-size representation, space- and time-scales, and objectives are not independent, but in combination determine the accuracy and effort associated with a transport estimate. Given the variety and complexity of natural channels and the number of purposes for which a transport estimate is useful, it is not surprising that many methods exist and it is unlikely that any single method would meet all objectives under all circumstances. This diversity should motivate a broader discussion of which methods might provide efficiency, accuracy and consistency in a wide range of situations. The exercise is worthwhile, given the potential benefit that a larger number of reliable transport estimates could provide to a wide range of basic and applied problems.

Of the various options available for making a transport estimate, this paper suggests a set of four that is likely to provide a favourable combination of accuracy and effort under typical circumstances. The first is to estimate transport rate using a formula calibrated by a small number of transport observations. The second is to use transport samples collected only at small transport rates, which provides important logistical and safety advantages while permitting the use of pit or fixed-net samplers, which can provide long-duration samples of sufficient accuracy to support a calibration based on limited sampling. The third element is to divide the full range of grain sizes into two fractions, which captures much of the sorting and differential transport processes characteristic of gravel-bed rivers, while reducing the field effort. The final element combines the measured transport rates, an approximate flow scaling, and a transport formula in a robust predictive framework that can be supported by a manageable field programme.

Most of these elements are not new individually, although this particular combination is not widely used and offers some particular advantages. For example, although pit samplers fill rapidly at large transport rates, thereby limiting their use in a fully empirical programme, they can sample for long periods at small transport rates, providing the accuracy needed if a calibrated estimate is to be based on a small number of samples at small rates. Similarly, a two-fraction transport model applied as a predictive formula requires field determination of the grain size of each fraction, a time-consuming procedure for a stream reach, whereas the calibrated approach presented here requires an accurate estimate of only the relative proportion of each fraction, which considerably reduces the field effort. Finally, using a few transport samples to calibrate a transport formula improves the accuracy of the formula prediction with much less effort than a fully empirical estimate.

The combination of methods presented here has not been tested in any formal manner. Indeed, formal testing would be difficult because the true transport rate is never known and because reliable estimates of the transport rate are available for only a few cases and these have been used to develop the empirical transport relations used in the method. Support for the individual elements, including the transport formulae, can be found in the references cited; conceptual arguments supporting their combined advantage are made here. The advantages of the combination are also illustrated with an example.

Evaluation of any method for estimating transport requires a clear definition of the objective. The specific objective here is a relationship between water discharge and total bed-material transport rate through a crosssection. This will be termed a bed-material rating curve, although no implications are made regarding whether the curve is stable in space or time. This is a limited but common objective, focused on describing the state of transport at a location at a specific time. Although broader considerations of how the sediment rating curve might change with season, climate, or land use are not addressed directly by the approach in this paper, it does provide an efficient means of monitoring and describing those changes. 


\section{MODELING, MEASUREMENT, AND THE CALIBRATION OPTION}

The typical choices for estimating bed-material transport in a gravel-bed river are to use a formula or to directly measure the transport rate, typically with portable samplers. Both require fieldwork; estimates from both may be expected to have considerable uncertainty. Broadly speaking, formula predictions require less effort, whereas field measurements offer the possibility of greater accuracy, but at greater effort. A third option, in which a few observations of small transport rates are used to improve the accuracy of formula predictions, may provide a superior combination of accuracy and effort.

The predictive approach uses any of a number of sediment transport formulae (e.g. Meyer-Peter and Müller, 1948; Ackers and White, 1972; Parker et al., 1982; review in Gomez and Church, 1989) to predict either the total bed-load transport or the transport rate of individual size fractions. An important advantage unique to the formula prediction is the ability to predict transport under conditions other than the present, making possible predictions of channel change. The information required includes the grain size of the river bed and the channel geometry of the reach. From these quantities, dimensionless parameters representing the flow and the sediment are calculated and used with the transport formula to predict the transport rate. Because the effectiveness of discharge in moving sediment varies with channel geometry, planform and roughness, a suitably scaled flow variable (typically bed shear stress $\tau_{0}$ or stream power) is required for a formula prediction. Formulae based on $\tau_{0}$ are used in this paper, although the concepts discussed apply equally to stream power.

An important source of error in the formula approach arises from the propagation of error in the measured variables used to calculate transport. McLean (1985) used plausible uncertainties in velocity, depth, slope and grain size to estimate the uncertainty in transport rates calculated for the Fraser River in British Columbia, Canada. Values of uncertainty in calculated transport, expressed as $\Delta q_{\mathrm{b}} / q_{\mathrm{b}}$ where $q_{\mathrm{b}}$ is transport rate and $\Delta q_{\mathrm{b}}$ is error in the transport rate, varied between \pm 0.4 to \pm 3.6 for five different transport formulae. Another source of error in the formula approach arises from spatial variability in $\tau_{0}$, which can be quite large, even in straight reaches with relatively simple cross-section (Wilcock et al., 1996). Where local values of $\tau_{0}$ differ from the mean, the sum of transport rates predicted using local values of $\tau_{0}$ will be greater than that predicted using the section mean. Paola et al. (1999) estimated that lateral topographic variability can increase transport rates through a section by as much as a factor of three. In the extreme, this ratio can approach infinity when substantial transport occurs in parts of a cross-section for which the mean $\tau_{0}$ predicts zero transport.

To account for spatial variation in both flow and sediment, it is possible to predict the local flow and transport field throughout a river reach, from which the total bed-material transport is found by cumulating the local transport across a section. Because the transport rate is sensitive to grain size at any point on the bed, such a modelling effort requires knowledge of the bed grain-size and topography throughout a reach. The effort required to determine this input can be very large, becoming impractical when the bed size distribution is subject to change, or when the transport for a number of streams must be forecast. A complete map of the local grain size and topography might be justified if it could be done only once; it is harder to support if the same effort must be made repeatedly as part of a broader study. A practical method for estimating transport is most likely to be based on an integral measure of grain size that may be monitored throughout a reach without time-consuming sampling.

The uncertainty involved in formula estimates of transport is evident in the fact that values reported for the critical dimensionless shear stress for incipient motion $\tau_{\mathrm{c}}^{*}$ vary over a range of approximately a factor of two (review in Buffington and Montgomery, 1997). Although part of this variation represents true differences in $\tau_{\mathrm{c}}^{*}$ owing to variation in bed properties such as grain packing, arrangement and cementation, the variability also arises from error in using an average to represent the spatially variable bed stress. Uncertainty in $\tau_{\mathrm{c}}^{*}$ of a factor of two produces unacceptable uncertainty in predicted transport rate, particularly at the small transport rates typical of many gravel-bed rivers.

An empirical relationship between transport rate and flow discharge may be developed directly from a large number of observations of the transport rate. A hand-held sampler typically is used to collect a small portion of the bed load. Sampling has the important advantage that the water discharge usually is measured along with the transport rate, thereby eliminating the intermediate step of scaling the discharge in order to predict transport rates. The trade-off is the effort required. Because of the large spatial and temporal variability 
characteristic of bed-load transport, measurement programs require a large number of samples (Emmett, 1980; Hubbell, 1987). When multiplied by the range of flows for which transport observations are needed, the effort required is large. Even with this effort, important sources of error remain. Transport may be overestimated by scooping immobile bed material or underestimated by allowing transport to pass beneath or around the sampler. Grains of a size that approaches or exceeds the opening of the sampler will not be sampled. More critically, the amount of transport collected in a standard sampling traverse (10 or 20 point samples, each with duration of order of $1 \mathrm{~min}$ ), is less (often much less) than 1 per cent of the transport passing through the section during the sampling period. A transport estimate based on such a small sample of a spatially and temporally variable transport field is likely to have considerable error. Even in the best of cases, scatter in transport observations is likely to exceed an order of magnitude and uncertainty in the predicted transport rate is difficult to reduce below \pm 50 per cent (cf. Hubbell, 1987; McLean and Tassone, 1987).

More accurate transport sampling may be conducted with pit traps, which catch nearly all of the bed material in transport and are able to sample for long periods (e.g. Church et al., 1991). Similar results may be obtained with net traps that can be attached to fixed platforms on the stream bed (Bunte et al., 2001). Because of a decrease in trap efficiency with decreasing grain size, there generally is a minimum grain size that can be sampled accurately in a pit trap. This size is comparable to the mesh size of portable and net samplers. The main drawbacks of pit or fixed net samplers are the installation effort and the fact that they can be inaccessible and can fill rapidly at large transport rates.

Neither formula predictions nor point sampling provide a combination of accuracy and effort that is likely to promote more frequent estimates of transport rate. A compromise, in which a transport formula is calibrated by a small number of transport samples, may provide a useful alternative. The approach suggested here is to use a small number of measurements of small transport rates to calibrate a predictive model, thereby increasing its accuracy. There are two keys to the success of this alternative: the number of samples should be small, thereby reducing effort, and the samples should be accurate, thereby allowing a small number of samples to truly improve the transport prediction. The goal of the transport observations is to determine the reference shear stress $\tau_{\mathrm{r}}$, a measurable surrogate for the critical shear stress at incipient motion $\tau_{\mathrm{c}}$. Most transport models contain a term such as $\tau_{0} / \tau_{\mathrm{c}}$ or $\tau_{0}-\tau_{\mathrm{c}}$, uncertainty in which is the dominant source of error in transport predictions. Transport measurements reduce the error in determining the discharge producing $\tau_{\mathrm{c}}$; the remaining and typically smaller source of error is in the estimate of the change in $\tau_{0}$ with discharge.

A calibrated approach to predicting transport rate has been suggested before, most recently by Bakke et al. (1999). In their method, standard hand-held samples over the range of transport rates are used to calibrate a transport formula for many different size fractions. Although broadly similar in that a calibrated application of a transport formula is used, the choices made here emphasize the advantages of a small number of longduration samples at small transport rates and the use of only one or two size fractions. Further, the method presented here is only weakly dependent on the accuracy of the estimate of bed grain-size.

\section{ACCURACY AND COST}

In order to evaluate the trade-off between accuracy and effort (or cost) for the formula, empirical and calibrated approaches, an approximate comparison is illustrated in Figure 1. Cost of data collection is assumed to include a fixed cost (e.g. field work to describe the channel reach) and a per-observation cost for a bed-load sampling traverse (Figure 1a). Formula prediction requires only the fixed start-up cost, whereas the empirical and calibrated methods include both a start-up and per-sample cost. In the illustration, the start-up cost is scaled to equal the cost of performing 10 bed-load sampling traverses.

Prediction accuracy is defined as $1-\Delta q_{\mathrm{b}} / q_{\mathrm{b}}$, where $q_{\mathrm{b}}$ is transport rate and $\Delta q_{\mathrm{b}}$ is a measure of the error in estimating $q_{\mathrm{b}}$. Accuracy does not vary with sample size for the formula approach, because transport samples are not used. For illustration, accuracy for the formula approach is assigned a value of zero, corresponding to an uncertainty of \pm 100 per cent in the calculated transport rate, which is within the range found by McLean (1985) in his error propagation analysis of formula predictions. Prediction uncertainty can be larger, particularly in cases with a significant lateral variation in transport rate. In the empirical approach, if a least-squares line is fitted to transport samples, the confidence limits on the estimated transport rate will 


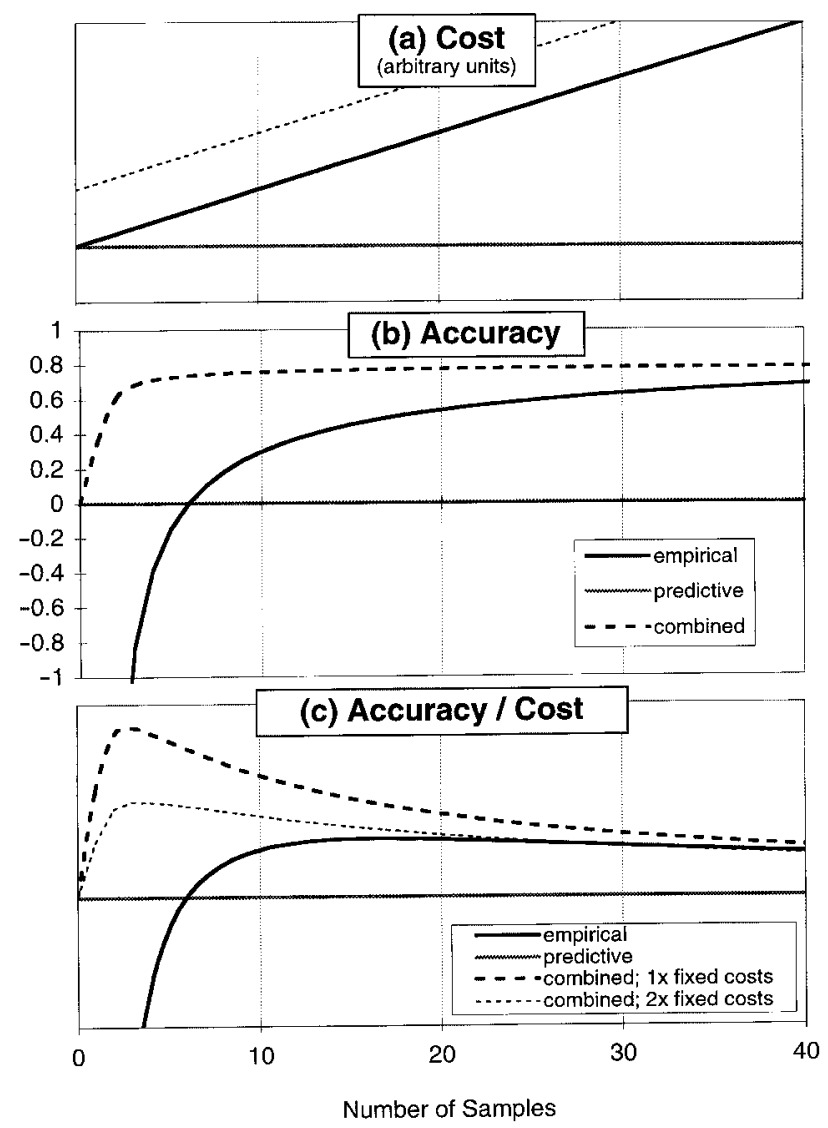

Figure 1. Schematic illustration of the accuracy/cost trade-off for estimating transport from transport samples alone (empirical), from a transport formula alone and from a combination of the two approaches in which transport samples are used to improve the accuracy of the predicted transport (calibrated). Accuracy for the formula prediction is assumed to be 0 (error $\Delta q_{\mathrm{b}} \approx q_{\mathrm{b}}$ ). Accuracy for the other two methods increases with the square root of sample number and depends on the sample standard deviation for the transport observations, which is assumed to be equal in magnitude to the measured transport rate (sample coefficient of variation is 1.0). For the calibrated approach, accuracy/cost ratio is calculated using the same fixed costs as the other methods (1x) and a fixed cost twice as large (2x)

vary as $\sigma /(N)^{0.5}$, where $\sigma$ is the sample standard deviation and $N$ is the number of samples. This estimate holds at the mean value of $Q$; the error in predicting transport will increase as $Q$ deviates from its mean. A coefficient of variation $\sigma / q_{\mathrm{b}}=1$ is used to calculate the accuracy of the empirical method (Figure 1b), chosen to approximate the sampling error for a channel with a simple transport field. An upper limit of 0.8 is assigned to the accuracy for the empirical approach, so the accuracy asymptotically approaches 0.8 at large $N$. For the calibrated approach, accuracy is assumed to equal that of the formula approach for zero samples and to equal that of the empirical approach at large $N$, with a proportional increase in accuracy with $N$ equal to that of the empirical approach.

The trade-off between accuracy and cost is represented as the ratio of the two, which gives an indication of value in the sense that a larger ratio implies more accuracy per cost (Figure 1c). For the formula case, accuracy does not vary with sample size, so the accuracy/cost ratio is a constant. For the empirical approach, the accuracy/cost ratio increases with $N$, reaches a maximum, and then decreases with $N$, as might be expected if cost increases linearly with $N$ and accuracy increases with its square root. For the sample standard deviation chosen, the maximum accuracy/cost ratio is obtained at $N=17$, although the accuracy/cost ratio is within 10 per cent of this value for $12<N<27$. Two values of cost are used to evaluate the accuracy/cost ratio for the calibrated approach: the same fixed cost as the other two methods and a fixed cost that is twice as large to account for installing pit or net traps in the bed. Because excavation for pit traps also provides bulk samples 
for grain-size analysis, the actual net cost of installing pit traps is likely to fall between these two values. In either case, the maximum value of the accuracy/cost ratio is larger than that of the empirical approach and occurs at much smaller sample size $(N=3)$.

The illustration in Figure 1 is, of course, not a prediction of any particular example, but serves to identify the main elements in the trade-off of accuracy and cost. The relative magnitude of some of the trends in Figure 1 will change if other values of accuracy are assigned to the different approaches. For example, the relative advantage of the formula and empirical approaches depend entirely on the value of accuracy assigned to the formula approach and the sample standard deviation and maximum accuracy assigned to the empirical approach. Other results may be robust. If the accuracy of the calibrated approach at $N=0$ can be assumed to equal that of the formula approach, and if the accuracy in both the empirical and calibrated approaches increases with the square root of sample size, then the accuracy and accuracy/cost ratio for the calibrated approach should exceed those of either of the other two and a maximum value of the accuracy/cost ratio, should it exist, will occur at a smaller $N$ for the calibrated approach. As long as one assumes that the formula approach has some accuracy and that calibration of the formula prediction improves its accuracy, it appears reasonable to conclude that a few transport samples will provide increased accuracy at moderate cost and a favourable accuracy/cost ratio.

\section{AN INTEGRAL MEASURE FOR MIXED-SIZE SEDIMENT}

If a completely empirical approach is taken in developing a sediment rating curve, the number of size fractions used is limited only by the effort required to sieve the transport samples. If either the formula or calibrated approach is used, an initial decision must be made regarding how to represent the wide range of grain sizes typically found in a gravel-bed river. Sufficient progress has been made in modelling the transport of widely sorted mixed-size sediment that, in the author's opinion, reliable predictions of the transport of different grain sizes can be made for homogeneous mixtures of sizes in simple flow fields. Extension of these methods to natural streams with variable topography and size composition is problematic. Although computational procedures have been developed to account for fractional transport and sorting in complex transport fields, the informational requirements of these methods are very large. Local grain-size distributions are required to calculate local transport rates, but such detail is time consuming to collect and unlikely to be practical as part of a larger study. A practical approach to estimating transport rates requires an integral measure, preferably leaving open the possibility of efficient repeat observations for the purposes of monitoring.

Considerable simplification can be achieved if transport predictions are made for a small number of grouped size fractions rather than for many finely divided size fractions. The empirical basis for such a grouping is the observation that the transport rates of different size fractions are often nearly the same (when transport rate is scaled by the proportion of each size fraction). In the limit of perfect similarity for all size fractions, this is the condition of equal mobility defined by Parker et al. (1982). Similar fractional transport rates are observed over the full range of grain-sizes in sediments with a unimodal grain-size distribution (Wilcock, 1993). Divergence from the common trend tends to be largest for the very smallest (sand) and largest fractions. Sediments with the largest deviations tend to have bimodal size distributions, with a principal gravel mode and a secondary sand mode (Kuhnle, 1992; Wilcock, 1992). For these sediments, sand is transported preferentially at smaller flows, as is often observed in the field (e.g. Jackson and Beschta, 1982; Ferguson et al., 1989). The difference between the sand and gravel transport rates motivated Kuhnle (1992) to suggest that sand and gravel transport might be modelled using different relationships. Paola and Seal (1995) modelled downstream fining using an assumption of equal mobility within sand and gravel fractions divided into locally sorted patches.

The simplest approximation is to treat the bed material as a single size fraction, predicting transport rates using a single characteristic grain-size, such as the median. This approach does not admit sediment sorting, however, and cannot predict the selective transport of fine sediments over a bed of coarser grains, an important feature of many gravel-bed rivers. Use of a single fraction can be effective if a transport estimate is required for only a subset of the bed size distribution. For example, the approach may be applied to only sand or sand plus pea-gravel fractions when routing fines through a gravel-bed river (Wilcock et al., 1996). In the example 
used later in this paper, the objective was to document the movement of very coarse sediment through a steep mountain river and the transport was estimated for only a subset of the gravel sizes.

Expanding the number of fractions from one to two allows the entire bed size distribution to be considered while remaining simple enough to permit a practical integral description of the sediment. A two-fraction estimate allows sand and gravel to move at different rates, thereby permitting change in bed grain-size owing to changes in the relative proportion of sand and gravel, if not the result of changes in the representative grain-size of either fraction. This provides a means of predicting the variation in the fines content of the bed, which often may be more variable than that of the coarse fraction, and whose passage, intrusion, or removal may be a specific environmental or engineering objective. A two-part transport relationship also admits relatively large sand transport rates at low to moderate flows.

In some cases, two fractions may not capture adequately the variation in transport rate from size to size. Parker et al. (1982) demonstrated small but systematic deviations from fraction-by-fraction transport similarity for Oak Creek using three sizes fractions. Wilcock and McArdell (1993) demonstrated that the scaled transport rates for the gravel fractions of a widely sorted sand-gravel mixture varied monotonically with grain-size. For widely sorted sediments, transport of the coarsest gravel fractions typically begins at a larger flow than that of the fractions in the pea gravel range and the grain-size of the gravel in transport increases with flow strength. A two-fraction model should not be used in cases, such as prediction of armouring, for which differences among gravel transport rates are important. Transport rates for sizes within the sand fractions appear to be more similar than for the gravel fractions, presumably a result of the fact that the forces exerted by near-bed flow in gravel-bed streams typically far exceed those necessary to initiate motion of the sand fractions.

A two-fraction approach offers some important potential advantages in terms of field effort. Once the proportion of one fraction (e.g. sand) is determined, the proportion of the other fraction (e.g. gravel) is simply the remainder of the bed. Once the sand content of different bed areas is determined from point counts or bulk samples, the proportion of sand on the bed may be found using a visual estimate. Areas with similar fines content may be mapped and combined to give a weighted average proportion of sand for the reach (Wilcock et al., 1996), giving an integral measure of grain-size with reasonable effort. If changes in bed size distribution are the result primarily of the introduction or removal of the fines from a reach, remapping of fines content provides a relatively quick evaluation compared with the effort required to characterize the full grain-size distribution of the upstream reach. Such an integral approach can provide an efficient basis for monitoring.

A further advantage of a two-fraction approach, when used in combination with a few transport samples in the calibrated methodology described later in this paper, is that the only grain-size information required to estimate transport rate is the relative proportion of fine and coarse sediment in the reach. The grain-size of the two grouped fractions is not needed. This is far less information than that required for a fractional transport model, and is comparable to the effort required for a total bed-load model based on a characteristic size of the bed.

The conceptual underpinning for a two-fraction approach rests on the different transport dynamics of grains forming the framework and matrix of a gravel-bed river. Although a strict definition of these two grain populations does not exist, the sand-gravel boundary $(2 \mathrm{~mm}$ ) provides a consistent, if ad hoc definition. Distinction between framework and matrix sizes is relatively straightforward for size distributions with a principal gravel mode, a secondary sand mode, and a small amount of sediment in the 'grain-size gap' within the $2 \mathrm{~mm}$ to $8 \mathrm{~mm}$ range. Gravel beds with no sand mode can be interpreted as openwork gravels with an absence of matrix. Other boundaries between fine and coarse sediment can be used consistently with a calibrated transport estimate. For example, a boundary at $8 \mathrm{~mm}$ has been used in a coarse gravel-bed river with a distinct fine mode in the sand and pea gravel range (Wilcock et al., 1996).

Wilcock (1997) used transport observations from four streams and one flume study to demonstrate that grouped sand and gravel transport rates collapse about two common relationships (one for sand, one for gravel) when the bed shear stress is scaled by an empirically defined reference shear stress for the sand and gravel. Reference shear stresses (Parker et al., 1982; Wilcock, 1988) for the sand $\tau_{\mathrm{rs}}$ and gravel $\tau_{\mathrm{rg}}$ were calculated as the value of shear stress producing the reference transport rate of $W^{*}=0.002$ where

$$
W_{i}^{*}=\frac{(s-1) g q_{\mathrm{b} i}}{f_{i} \rho_{\mathrm{s}}(\tau / \rho)^{1.5}}
$$




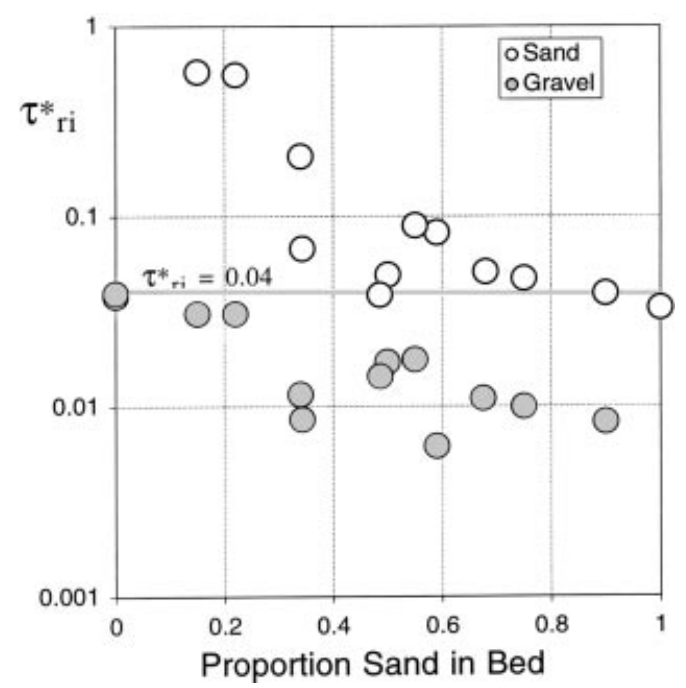

Figure 2. Variation with sand content of dimensionless reference shear stress for four streams and ten laboratory sediments. Standard values for clean gravel and clean sand are $c .0 \cdot 04$. Values decrease between 15 and 50 per cent sand, corresponding to the transition between framework-supported and matrix-supported sediments. Consistent trends for all sediments implies a usable consistency for the two-fraction model of transport

where $s$ is $\rho_{\mathrm{s}} / \rho, \rho_{\mathrm{s}}$ is sediment density, $\rho$ is fluid density, $g$ is acceleration of gravity, $f_{i}$ is the proportion of fraction $i$ in the bed, $q_{\mathrm{b} i}$ is transport rate in units of mass per unit width and time, and the subscript $i$ represents either the sand or the gravel fraction.

In addition to demonstrating an acceptable collapse about a common trend, a suitably general transport similarity analysis must demonstrate a consistent and plausible basis for the values of the essential scaling parameter, in this case, $\tau_{\text {ri }}$. Values of dimensionless reference shear stress

$$
\tau_{\mathrm{ri}}^{*}=\frac{\tau_{\mathrm{ri}}}{\left(\rho_{\mathrm{s}}-\rho\right) g D_{i}}
$$

for the two-fraction similarity collapse were shown to vary consistently with sand content between standard values at the limits of clean sand and gravel (Figure 2; Wilcock, 1998). At small values of sand content (clean gravel), $\tau_{\mathrm{rg}}^{*}$ approaches a standard value of approximately 0.04. The reference shear stresses drop consistently for both sand and gravel over a range in sand content of approximately 15-50 per cent, corresponding to the appearance of sand patches on the bed surface and the transition from a framework-supported to a matrix-supported bed. Variation in $\tau_{\mathrm{ri}}^{*}$ is relatively small for sand content larger than approximately 50 per cent. Values for $\tau_{\mathrm{rs}}^{*}$ approach the value for clean sand $(\approx 0.04)$ and $\tau_{\mathrm{rg}}^{*}$ approaches a minimum of order 0.01, suggesting that the incipient motion of gravel on a sand bed is not influenced by relative roughness and is controlled by the balance between gravel mass and shear stress (Wilcock, 1998). The variation of $\tau_{\mathrm{ri}}^{*}$ in Figure 2 is consistent with a change in transport behaviour from gravel-influenced to sand-influenced at the transition from a framework to matrix-supported bed, suggesting that a two-fraction model may provide a general and useful description of transport dynamics in gravel-bed rivers.

\section{SAMPLING TRANSPORT RATE}

If a transport formula is to be calibrated using only a small number of samples, it is essential that the samples be accurate. Given the spatial and temporal variability in transport, this means that very long samples in a spatially dense array are needed in order to ensure that the proportion of transport sampled is as large as practical. Such a sampling plan can be achieved by sampling with pit traps, which can sample many sites simultaneously for long periods of time. The principal drawbacks of pit samplers are that they fill quickly 
at larger transport rates and may be difficult to clean at high flows. These constraints place an upper limit on the transport rates that may be sampled. In the approach proposed here, however, transport observations are used to determine values of $\tau_{\mathrm{rg}}$ and $\tau_{\mathrm{rs}}$ and measurements need be made only at small transport rates. Limiting transport observations to relatively small flows also has important safety and logistical advantages.

Bed-load traps may be conveniently made of 20-L ( 5 gallon) pails, although other containers also may be used. It is important that the container be relatively deep compared with its width, in order to decrease the strength of eddies that might sweep sediment out of the trap. A baffle within the bucket can help to reduce eddy motion and loss of fines. It is an advantage to have a practical means of removing the trap. Church et al. (1991) drove a $30.5 \mathrm{~cm}$ (1 ft.) diameter pipe in the bed, into which they inserted the 20-L buckets. McArdell (personal communication, 1996) inserted buckets directly into a hole in the bed and then placed porous microfibre plastic sediment bags (commercially used for sand) inside the buckets. Sample bags could be quickly removed and replaced with a fresh bag. The bags were secured to the top of the bucket with large rubber bands and a large painted cobble was placed inside the bag to hold it in place. Tight fitting or weighted lids are desirable to keep the traps from filling when not in use.

The number of traps used should be sufficient to give a representative sample across the entire active bed of the channel. One-half the width of active bed-material transport is a useful goal. Although bed excavation for trap installation requires considerable effort, the excavated sediment does provide a bed sample of sufficient volume to accurately determine the size distribution of many gravel beds. Excavation, as well as trap emptying, may be possible with suction pumps used by amateur placer miners. In instances where trap installation is not possible (e.g. because of shallow bedrock or safety considerations), it may be possible to install fixed net traps (Bunte et al., 2001) during the period of sampling. Because of the long sample periods required and the sensitivity to sampling error, it is unlikely that hand-held samplers could be used to effectively sample at the small transport rates suggested here.

\section{TRANSPORT FORMULA}

A calibrated estimate of transport rate requires specification of a transport function, although it should be emphasized that most of the accuracy in the estimate is gained by calibrating the formula rather than in the choice among many of the common formulae. Wilcock (1997) found that the Parker (1979) transport relationship

$$
W_{i}^{*}=11 \cdot 2\left(1-0.846 \frac{\tau_{\mathrm{ri}}}{\tau}\right)^{4.5}
$$

provides a good fit to the grouped gravel transport rates for four streams and one laboratory sediment. This relationship is very similar in form to the Einstein (1950) bed-load curve and has been found to represent gravel transport well in many streams. Gravel transport data typically fall in the range above a reference transport rate of $W^{*}>0.0025$, including the grouped data used by Wilcock (1997). In some cases, however, particularly in very steep, coarse-bedded streams, transport rates may be much smaller than this reference transport rate. Based on the laboratory results of Proffitt and Sutherland (1983) and Paintal (1971), Parker (1990) found that the following relationship

$$
W_{i}^{*}=0.0025\left(\frac{\tau}{\tau_{\mathrm{ri}}}\right)^{14 \cdot 2}
$$

provided a superior fit for small transport rates. The values of the two functions match at $\tau / \tau_{\mathrm{ri}}=1$; Equation 3 is used for $\tau / \tau_{\mathrm{ri}}>1$ and Equation 4 for $\tau / \tau_{\mathrm{ri}}<1$. For the grouped sand fractions, Wilcock (1997) found that a slight modification of the Parker (1979) relationship

$$
W_{i}^{*}=11 \cdot 2\left(1-0.846 \sqrt{\frac{\tau_{\mathrm{ri}}}{\tau}}\right)^{4 \cdot 5}
$$


provides a good collapse of the transport data. Sand transport rates smaller than the reference transport rate are exceedingly small and there is no practical need for a separate sand transport function.

\section{DEVELOPMENT OF A SEDIMENT RATING CURVE}

The inputs needed to develop a sediment rating curve are the fraction of gravel and sand in the bed, a rating curve for section mean velocity, and measured sand and gravel transport rates. A remarkable feature of the calibrated approach presented here is that the sand and gravel grain-sizes are not needed, as long as $\tau_{\mathrm{rs}}$ and $\tau_{\mathrm{rg}}$ are found from transport samples. A characteristic grain-size is needed to estimate skin friction, although it will be shown below that the final transport estimate does not depend strongly on the choice of grain-size. Three steps are required to develop the rating curve: a drag partition to determine skin friction, specification of $\tau_{\mathrm{rs}}$ and $\tau_{\mathrm{rg}}$, and calculation of the rating curve from the appropriate transport relationship.

Calculation of skin-friction in a gravel-bed river is notoriously difficult, particularly in steep gravel-bed streams, and is an important source of error in formula predictions of transport rate. An important objective of the method given here is to reduce the dependence of the calculated transport on the details of the skin friction calculation. Wilcock (1996) demonstrated that the most precise estimate of local stress is achieved using the flow depth and depth-averaged velocity in a flow resistance type relationship, because these variables can be measured with more accuracy than variables such as energy slope and near-bed velocity that are used in other methods. A similar argument is likely to apply for the section-averaged stress, if a formulation is used in which the mean skin-friction stress depends primarily on the mean velocity and flow depth, both of which can be estimated with reasonable accuracy. A suitable relationship is the power approximation to the Keulegan log profile

$$
\frac{U}{u_{*}}=8 \cdot 1\left(\frac{h}{k_{\mathrm{s}}}\right)^{0.167}
$$

where $U$ is mean flow velocity, $h$ is flow depth, $u_{*}$ is the bed shear velocity equal to $(g h S)^{0.5}$ and $k_{\mathrm{s}}$ is grain roughness. To estimate grain stress, $k_{\mathrm{s}}=2 D_{65}$, where $D_{65}$ is calculated relative to the size distribution of transportable sediment (essentially the argument underlying the approximate drag partition of Einstein, 1950). Using $u_{*}=(g h S)^{0.5}$, solving Equation 6 for $h$, and substituting $\tau=\rho g h S$, a relationship for $\tau$ is obtained

$$
\tau=0.052 \rho\left(g S D_{65}\right)^{0.25} U^{1.5}
$$

Precision in values of $S$ and $D_{65}$ is not particularly important because they are present in Equation 7 only to the power of $0 \cdot 25$. More importantly, $\tau$ is present in the transport formulae in the form $\tau / \tau_{\mathrm{ri}}$. Writing Equation 7 twice, once for $\tau$ and once for $\tau_{\mathrm{ri}}$, and taking their ratio gives

$$
\frac{\tau}{\tau_{\mathrm{ri}}}=\left(\frac{U}{U_{\mathrm{ri}}}\right)^{1.5}
$$

indicating that the increase in $\tau$ relative to $\tau_{\mathrm{ri}}$ depends on $U$ alone. If, for example, $U$ is a power function of $Q, U=a Q^{b}$, Equation 8 becomes

$$
\frac{\tau}{\tau_{\mathrm{ri}}}=\left(\frac{Q}{Q_{\mathrm{ri}}}\right)^{1.5 b}
$$

indicating that the controlling independent variable in the transport formulae depends only on $Q$ when a calibrated estimate of incipient motion is available. Because $\tau$ is also present in $W^{*}$, the final estimate of transport is not entirely independent of Equation 7, although the choice of $S$ and $D_{65}$ still has a minor effect on the estimated transport relationship, particularly at the small transport rates characteristic of gravel-bed rivers.

Values of $\tau_{\text {ri }}$ and the sediment rating curve can be determined in one straightforward computational step. Measured transport rates are plotted as a function of discharge. For a range of discharge spanning the 
transport observations and extending to higher flows, $U$ is found from a velocity-discharge relationship, $\tau$ from Equation 7, and $q_{\mathrm{b}}$ from Equations 3, 4, or 5 as appropriate. This transport relationship is superimposed on the measured data and values of $\tau_{\mathrm{rs}}$ and $\tau_{\mathrm{rg}}$ are adjusted to fit the transport function to the measured data.

\section{EXAMPLE}

The calibrated approach is illustrated here using transport observations from East St Louis Creek, a small, steep boulder-step stream in the Fraser Experimental Forest, Colorado, USA. Stream width is $2.8 \mathrm{~m}$ and mean slope above the measurement site is nearly 7 per cent. The bed material has $D_{50}=36 \mathrm{~mm}, D_{90}=200 \mathrm{~mm}$, and 20 per cent sand. Roughness and skin friction are difficult to estimate for such streams, making prediction from a transport formula highly uncertain. Flow and transport also are complex and difficult to measure, emphasizing the advantage of a calibrated approach for grouped transport rates, based on long-duration samples. Transport was measured only for grains coarser than $25 \mathrm{~mm}$, with the goal of documenting the transport of very coarse sediment in a steep mountain stream. The example does not illustrate a two-fraction model for all sizes (applicability of a two-fraction estimate to the transport of all sizes is discussed in Parker et al., 1982; Kuhnle, 1992; Wilcock, 1997, 1998), but does illustrate the approach advocated here for a subset of the gravel sizes under circumstances for which transport estimates are very difficult to make.

Transport sampling took advantage of a weir pond installed on the stream. Coarse gravel transport was caught in two wire-mesh baskets suspended at the upstream lip of the pond. The baskets were $0.3 \mathrm{~m}$ deep, $0.6 \mathrm{~m}$ in the downstream direction, $1.2 \mathrm{~m}$ in the cross-stream direction, and sampled approximately 55 per cent of the active transport width entering the pond. Wire mesh was $25 \mathrm{~mm}$; transport of finer grains was not sampled. Sample duration varied between $1.3 \mathrm{~h}$ and $99 \mathrm{~h}$. More than 90 per cent of the sample periods were longer than $3 \mathrm{~h}$ and the cumulative sample duration was $1817 \mathrm{~h}$. Samples were collected during spring runoff in 1996 and 1997. The return period of the peak daily discharge in 1997 exceeded 3 years. During peak runoff, daily fluctuations in discharge were regular but relatively small (5-15 per cent of peak daily discharge); daily fluctuations were minimal at other times. The entire duration of each sample period was used to determine transport rate, possibly underestimating transport rates during periods with discharge fluctuations, although these observations were indistinguishable from samples taken during periods with nearly constant discharge. Because of the extremely steep transport relationship, most of the daily transport occurs near the maximum daily discharge and gravel transport rate is plotted in Figure 3 as a function of the maximum discharge during each sampling period.

The coarse gravel transport rates follow a remarkably well-defined relationship with $Q$ (Figure 3). It is unlikely that such coherence could be achieved using the shorter sample periods typical of hand-held samplers, particularly at the very small transport rates observed on this stream. Such coherence is required if only a few transport samples are to be used to calibrate a transport formula. Although the data in Figure 3 are sufficient to define a fully empirical sediment rating curve, they serve the purpose here of illustrating how a sediment rating curve could be developed from a small subset of the transport samples. Any choice of a half-dozen points spanning the range of discharge would yield essentially the same position of the fitted curve (i.e. the value of $\tau_{\mathrm{rg}}$ ).

Discharge observations were used to develop a power function between discharge and mean velocity, which was used with Equation 7 to calculate $\tau$ for different values of $Q$. The gravel rating curve was based on Equation 4 and $\tau_{\mathrm{rg}}$ adjusted to provide the fit shown on Figure 3 . The fitted value of $\tau_{\mathrm{rg}}$ corresponds to $\tau_{\mathrm{rg}}^{*}=0.039$ for $D_{50}$ of the bed material, a typical value for incipient motion of coarse material in a gravel bed. The range of error possible with a transport formula is illustrated by plotting the same transport curves using $\tau_{\mathrm{rg}}^{*}$ equal to 0.03 and 0.06 , which encompass most of the commonly observed range in critical Shields Number. The range in estimated transport rate is several orders of magnitude, indicating the increased accuracy that can be achieved by calibrating the transport estimate.

\section{CONCLUSION}

Basic and applied problems in geomorphology would benefit from a reliable and efficient method for estimating transport rates in gravel-bed rivers. This is particularly clear in the case of sediment budgets, for which 


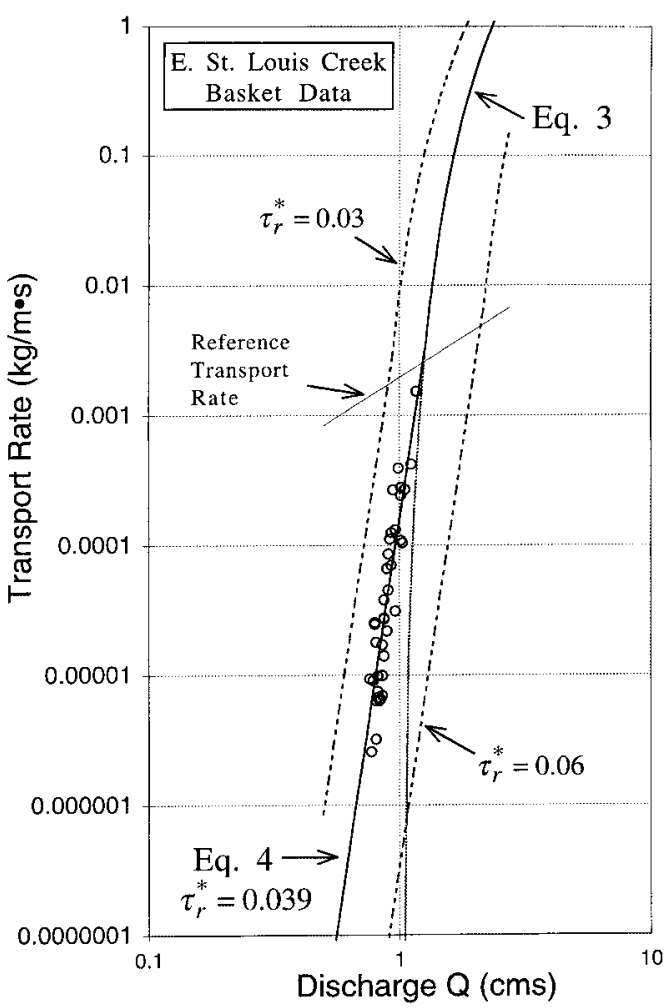

Figure 3. Transport rates for material coarser than $25 \mathrm{~mm}$ in East St Louis Creek, Colorado. Equation 4 is fitted to the data using a dimensionless reference shear stress $\tau_{\mathrm{r}}^{*}$ of 0.039 ; transport rating curves also estimated for $\tau_{\mathrm{r}}^{*}=0.03$ and $\tau_{\mathrm{r}}^{*}=0.06$, to illustrate the error possible with a priori choices of $\tau_{\mathrm{r}}^{*}$. Relationship between $Q$ and shear stress based on Equation 9 with exponent $b$ determined from an empirical velocity rating curve

spatial and temporal resolution depends on the number of sites at which verified estimates of sediment flux can be developed. Predictions of transport from a formula are not sufficiently accurate; development of an empirical rating curve is sufficiently time-consuming to prevent widespread application to larger scale problems. A more efficient approach is suggested here, in which transport is predicted using a formula and calibrated using a small number of observations of transport rates. Only small transport rates are sampled, avoiding the logistical and safety problems associated with measuring large transport rates and permitting use of a pit sampler to obtain accurate measurement of small transport rates. Combined with skin-friction and transport functions, the calibrated approach makes the transport prediction nearly independent of field measurements of slope and bed grain-size, which can be difficult to measure accurately. The bed grain-size distribution can be divided into two fractions, sand and gravel, which can be mapped as part of an efficient integral description of the bed. A two-fraction approach captures an important source of size sorting in streams. The method can be applied to either the sand or gravel fraction alone, or to a subset of the gravel sizes.

Although the approach presented here offers a favourable combination of accuracy and effort, the work involved in developing an estimate based on local information is non-trivial. Initial field work is likely to require at least two days for a small stream with a regular channel; more time would be required for larger or more complex channels. Multiple return visits are needed to clean the pit traps, although these may require less than an hour per site and a single person should be able to monitor a number of sites. This effort is considerably less than that required for a developing a full empirical sediment rating curve; it is not substantially larger than that required for a formula prediction, but offers greater accuracy.

There are limitations to the approach proposed. It relies on accurate measurement of small transport rates, which may be achieved with pit or net traps. There are streams with shallow bedrock, large amounts of 
organic debris, or liability concerns for which a practical in situ sampling method may not be possible. This type of sampling also is limited to smaller streams in which the pit traps are accessible. These problems do not reduce the need for practical, reliable, and consistent transport estimates and the development of such methods should be a priority.

\section{ACKNOWLEDGEMENTS}

This work was supported by the National Stream Systems Technology Center, under Partnership Agreement 28-CCS5-019 between the Johns Hopkins University and The U.S. Forest Service Rocky Mountain Forest and Range Experiment Station.

\section{REFERENCES}

Ackers P, White WR. 1973. Sediment transport: new approach and analysis. Journal of the Hydraulics Division, American Society of Civil Engineers 99: 2041-2060.

Bakke PD, Basdekas PO, Dawdy DR, Klingeman PC. 1999. Calibrated Parker-Klingeman model for gravel transport. Journal of Hydraulic Engineering 125: 657-660.

Buffington JM, Montgomery DR. 1997. A systematic analysis of eight decades of incipient motion studies, with special reference to gravel-bedded rivers. Water Resources Research 33: 1993-2029.

Bunte K, Abt SR, Potyondy JP. 2001. Portable bedload traps with high sampling intensity for sampling gravel and cobble bedload transport in wadable mountain streams. Seventh Federal Interagency Sedimentation Conference, 25-29 March, Reno, Nevada.

Church M, Wolcott JF, Fletcher WK. 1991. A test of equal mobility in fluvial sediment transport: behaviour of the sand fraction. Water Resources Research 27: 2941-2951.

Einstein HA. 1950. The Bedload Function for Sediment Transport in Open Channel Flows. Technical Bulletin 1026, United States Department of Agriculture, Soil Conservation Service: Washington, DC.

Emmett WW. 1980. A field calibration of the sediment-trapping characteristics of the Helley-Smith bedload sampler. United States Geological Survey Professional Paper 1139: 44 pp.

Ferguson RI, Prestegaard KL, Ashworth PJ. 1989. Influence of sand on hydraulics and gravel transport in a braided gravel bed river. Water Resources Research 25: 635-643.

Gomez B, Church M. 1989. An assessment of bed load sediment transport formulae for gravel bed rivers. Water Resources Research 25: $1161-1186$.

Hubbell DW. 1987. Bed load sampling and analysis. In Sediment Transport in Gravel-bed Rivers, Thorne CR, Bathurst JC, Hey RD (eds). Wiley: Chichester; 89-106.

Jackson WL, Beschta RL. 1982. A model of two-phase bedload transport in an Oregon coast range stream. Earth Surface Processes and Landforms 9: 517-527.

Kuhnle RA. 1992. Fractional transport rates of bedload on Goodwin Creek. In Dynamics of Gravel-bed Rivers, Billi P, Hey RD, Thorne CR, Tacconi P (eds). Wiley: Chichester; 141-155.

McLean DG. 1985. Sensitivity analysis of bedload equations. Proceedings Canadian Society for Civil Engineering, Annual Conference, Saskatoon, 27-31 May; 1B: 1-15.

McLean DG, Tassone B. 1987. Discussion of Hubbell, DW. 'Bed load sampling and analysis'. In Sediment Transport in Gravel-bed Rivers, Thorne CR, Bathurst JC, Hey RD (eds). Wiley: Chichester; 109-113.

Meyer-Peter E, Müller R. 1948. Formulation for bed load transport. Proceedings International Association for Hydraulic Research, 2nd Congress, Stockholm; 39-64.

Paintal AS. 1971. Concept of critical shear stress in loose boundary open channels. Journal of Hydraulic Research 9: 91-113.

Paola C, Seal R. 1995. Grain size patchiness as a cause of selective deposition and downstream fining. Water Resources Research 31: $1395-1407$.

Paola C, Parker G, Mohrig D, Whipple K. 1999. The influence of transport fluctuations on spatially averaged topography on a sandy, braided fluvial fan. In Numerical Experiments in Stratigraphy: Recent Advances in Stratigraphic and Sedimentologic Computer Simulations, Harbaugh J, Watney WL, Rankey EC, et al. (eds). Society of Economic Paleontologists and Mineralogists: Tulsa, OK; $211-218$.

Parker G. 1979. Hydraulic geometry of active gravel rivers. Journal of the Hydraulics Division, American Society of Civil Engineers 105: $1185-1201$.

Parker G. 1990. Surface-based bedload transport relation for gravel rivers. Journal of Hydraulic Research 28: 417-436.

Parker G, Klingeman PC, McLean DG. 1982. Bedload and size distribution in paved gravel-bed streams. Journal of the Hydraulics Division, American Society of Civil Engineers 108: 544-571.

Proffitt GT, Sutherland AJ. 1983. Transport of non-uniform sediments. Journal of Hydraulic Research 21: 33-43.

Schick AP, Lekach J. 1993. An evaluation of two ten-year sediment budgets, Nahal Yael, Israel. Physical Geography 14: $225-238$.

Wilcock PR. 1988. Methods for estimating the critical shear stress of individual fractions in mixed-size sediment. Water Resources Research 24: 1127-1135.

Wilcock PR. 1992. Experimental investigation of the effect of mixture properties on transport dynamics. In Dynamics of Gravel-bed Rivers, Billi P, Hey RD, Thorne CR, Tacconi P (eds). Wiley: Chichester; 109-139.

Wilcock PR. 1993. The critical shear stress of natural sediments. Journal of Hydraulic Engineering 119: 491-505.

Wilcock PR. 1996. Estimating local bed shear stress from velocity observations. Water Resources Research 32: $3361-3366$ 
Wilcock PR. 1997. A Method for Predicting Sediment Transport in Gravel-bed Rivers. Report to the United States Forest Service, Rocky Mountain Forest and Range Experiment Station: FortCollins, CO.

Wilcock PR. 1998. Two-fraction model of initial sediment motion in gravel-bed rivers. Science 280: 410-412.

Wilcock PR, McArdell BW. 1993. Surface-based fractional transport rates: mobilization thresholds and partial transport of a sand-gravel sediment. Water Resources Research 29: 1297-131.

Wilcock PR, Barta AF, Shea CC, Kondolf GM, Matthews WVG, Pitlick JC. 1996. Observations of flow and sediment entrainment on a large gravel-bed river. Water Resources Research 32: 2897-2909. 